\title{
A STUDY ON DRUG ABUSE IN ZAGAZIG UNIVERSITY STUDENTS, EGYPT: CROSS SECTIONAL STUDY
}

\author{
Dalia M. Amin, Zeinab A. Mohamed \\ Forensic Medicine and Clinical Toxicology Department \\ Faculty of Medicine - Zagazig University - Egypt \\ Corresponding author: Dr. Dalia Amin \\ Email: daliaamin013@gmail.com \\ Mobile:00201013585266
}

\begin{abstract}
Background: Drug addiction is a major public health and socioeconomic problems worldwide that annoy the Egyptian government, as it deals with younth within the age of productivity. Aim of the Work: To assess drug abuse among Zagazig University students, also to identify the most common abused drug among them. Subjects and Methods: A cross-sectional study conducted on 750 students in Zagazig University during the period from the beginning of November 2015 to the end of November 2016, after taken consent . Data of the students were taken from the questionnaire filled by students and the results of screening urine samples. Results: The prevalence of smoking among all studied students was $16.81 \%$ and strongly related to gender as in total males $26.1 \%$ were current smokers while in total females only $1.4 \%$; while, the prevalence of abusing alcohols was $6 \%$ of all studied students and all of them were males. The prevalence of drug abuse was $7.41 \%$ among all studied students. The most abused drug was tetrahydrocannabinol $(3.9 \%)$ followed by tramadol $(1.9 \%)$ then benzodiazepines $(0.67 \%)$, while, opium and barbiturates each one of them $(0.47 \%)$. Polydrug users were about $18 \%$ which were only males. The tramadol was the commonest drug to use in polydrug users. Conclusion: Drug abuse in Zagazig university students is very serious problem damaging the youth and the community.
\end{abstract}

Recommendation: Future longitudinal studies should be conducted to investigate the risk factors of drug abuse and suggest the use of urine analysis for drugs of abuse for all students before joining the university.

Keywords: Abuse, Addiction and Students.

\section{INTRODUCTION}

$\mathbf{T}$ The Young adulthood, ages 15-24, is a period of rapid economic, social, and cultural transitions in Egypt have created a favorable. condition for increased socially disruptive pattern of drugs and alcohol use. Substance abuse is a growing problem in Egypt, as in many developing countries (Hamedi et al, 2016).

In Egypt, university students is very important category that liable to depend on the drugs. This is very serious problem worry both the people and government; however, data on drug dependence are still few (El-Sawy et al., 2010). Very few survies have reported the incidence of misuse and dependency on substances among these students (Monirpoor et al., 2014).

Young adults aged 15-24 years constituted about $20 \%$ of the population in Egypt in 2000 (Refaat, 2004). Hence, we must pay attention toward the younger age of drug abusers and the increase in the discovery of some of drugs of abuse with the progressive poisoning pattern over years (El-Masry et al., 2013).

The aim of this work to assess drug abuse among Zagazig university students, also to identify the commonest drug abuse.

\section{SUBJECTS AND METHODES}

A cross-sectional survey was done on 750 Zagazig university students of both sexes from November 2015 to November 2016.

University students were 750 of both sexes randomly chosen from theoretical college (Commerce College and Law College), and practical college (Medicine, Pharmacy, Science and Nursing College). Ethical consideration was taken from Ethical Committee of Zagazig 
medicine faculty. An oral approval and written consents to answer the questionnaire and urine samples were taken.

A questionnaire sheet was developed specifically to collect data related to this study from students to assess the pattern of drug abuse among students. It included sociodemographic data and student's types of drugs abused.

Urine samples were screened by dipstick test named (ABONTM Multi-Drug) which is one step screening test panel(Figures1.2 and3)( used for qualitative detection of drugs of misuse which includes analgesic (tramadol), tetrahydrocannabinol,

(stimulants) amphetamine, Cocain, (sedative) opiate, barbiturate, and benzodiazepines. Only positive cases were confirmed by gas chromatography.

The collected data were statistically analyzed using Statistical Package for the Social Science version 16 program. Descriptive statistics were calculated (e.g., frequency, percentage, mean and standard deviation [SD]). Quantitative continuous analyzed using Student's $t$ - or ANOVA-tests. Qualitative data were compared using Chi-square test. $P$ value was considered significant if it was $<0.05$.

\section{RESULTS}

The age distribution of this studied population was within the range 17-24 years. The age between (19-20 years old) was 52\%,,(21-22 years old) was $35 \%$, (23-24years old) was $2.8 \%$ and (17-18 years old) was $10.2 \%$ of the studied students as shown in (Fig. 4). The mean age for all studied students in this study was $20.03 \pm 1.31$ years. The males were about $62.4 \%$ of all studied population while the other $37.6 \%$ were females.

Regarding the prevalence of smoking among all studied students was $16.81 \%$.

With highly significant differences between males and females (males 26.1 and females 1.4\%) (Table 1).

The prevalence of analgesic abuse among all studied students was $69.2 \%$ and there was no significant differences between males and females (males 64.9\%, females 73.9\%) (Table 2).

The prevalence of alcohol using among all studied students was $10.29 \%$ and there was highly significant differences between males and females (males $16.5 \%$ were currently using alcohol and $6.5 \%$ used it once while $0 \%$ in females were currently using alcohol and only $2.1 \%$ used it once) (Table 3).

While The prevalence of sedative abuse among all studied students was $5.2 \%$ but there was no significant differences between males and females (males 5.2\% ,1 females 5.2\%) (Table 4).

Also the prevalence of stimulant abuse among all studied students was $4 \%$ and there was significant differences between males and females (males 6.5\%, females 1.25\%) (Table 5).

There were significant difference between smokers abusing drugs \&alcohol and nonsmoker abusing them. As $44.21 \%$ of alcoholic were smokers while $3.6 \%$ were nonsmokers. And $19.79 \%$ of students misusing sedatives were smokers while $3.25 \%$ of them were nonsmokers. Also23.68 \% of students abusing stimulants were smokers while $2.38 \%$ of them were nonsmokers (Table 6).

There was significant difference between the screening of all the drugs between the males and the females( $11.67 \%$ and $0.84 \%$ respectively).

The percentages of positively screened students of all studied population were $3.9 \%, 1.9 \%$, $0.67,0.47$ and $0.47 \%$ for tetrahydrocannabinol, tramadol, Benzodiazepine, opium and barbiturate while there was negative screening for the amphetamin and cocaine. (Table 7).

The polydrug users among the positive studied population was $18 \%$ (Fig. 5).

There is strong association between the drug abuse and failure in the exam. There was were significant difference between positively screened students failed and un failed in the exam before (21.05\% and 3.3\% respectively )(Table 8). 


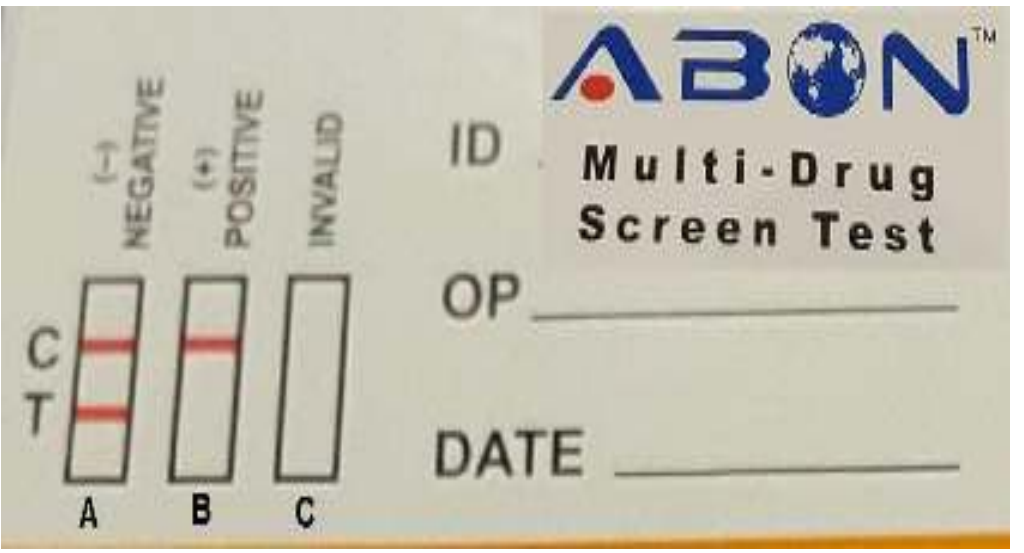

Figure 1: Interpretation of urine screening test; (A) negative, (B) positive, and (C) invalid test

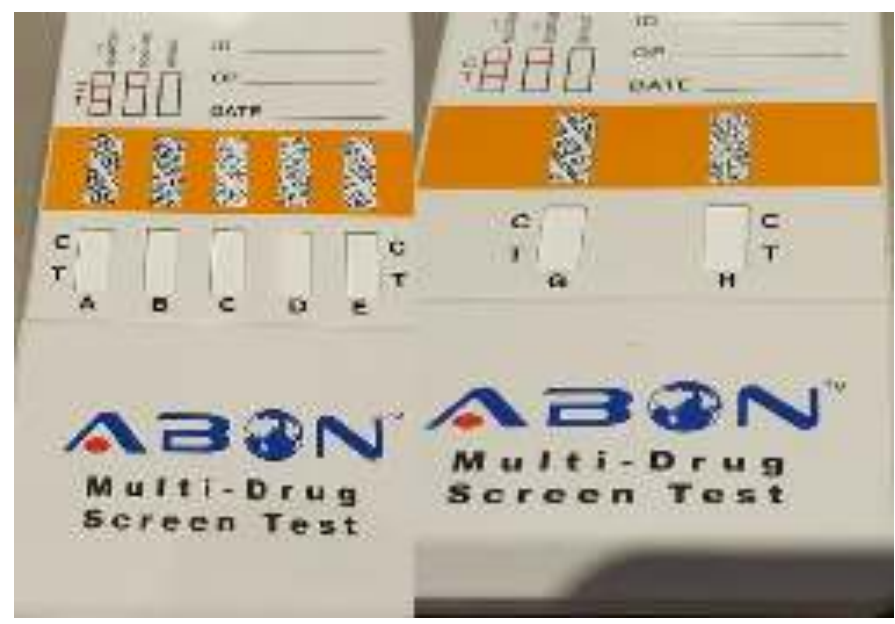

Figure 2: Drug detected by urine screening test; (A) cocain, (B) amphetamine, (C) THC, (D) opioid, (E) tramadol, (F) Barbiturate and (H) Benzodiazepine.

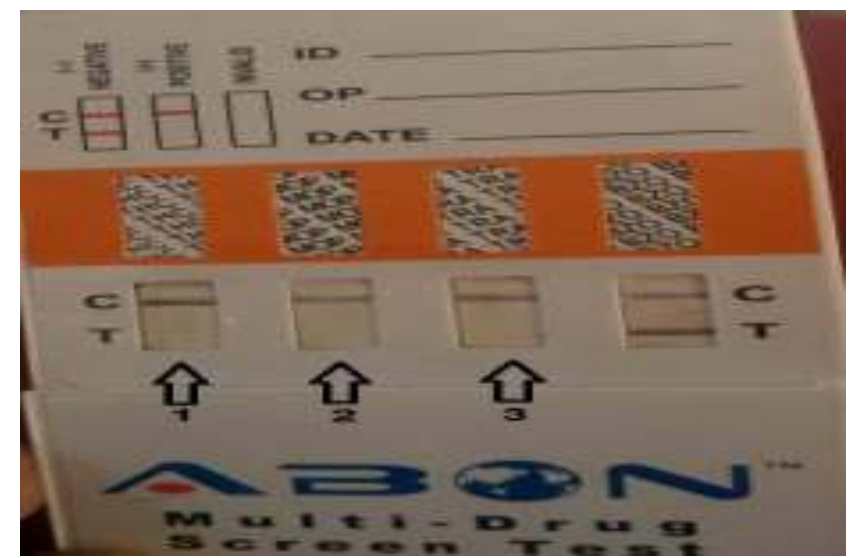

Figure 3: Positive test for TCH (arrow1), opioide (arrow2) and tramadol (arrow3) 


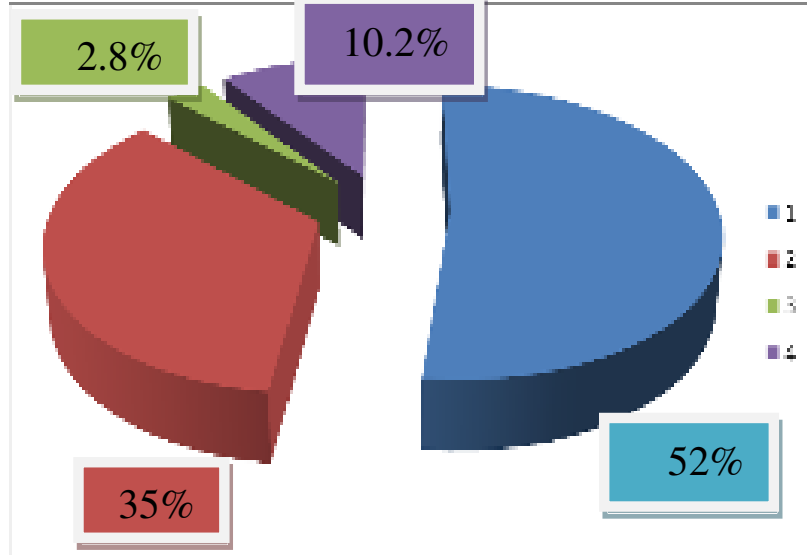

Figure 4: Age distribution among studied population 1(19-20)-2 (21-22)-3 (23-24) and 4(17-18).

Figure 5: Percentage of polydrug users (1) among the positive studied population

Table 1: Smoking prevelance and gender relationship among 750 students in Zagazig University (2016-2017).

\begin{tabular}{|c|c|c|c|c|}
\hline Smoking & Males & Femals & Total & $P$ value \\
\hline & $N=468(\%)$ & $N=282(\%)$ & $\begin{array}{c}N=750 \\
(\%)\end{array}$ & \\
\hline Yes & 26.1 & 1.4 & 16.81 & $<0.0001 *$ \\
\hline No & 73.9 & 98.6 & 83.19 & \\
\hline
\end{tabular}

* Significant.

Table 2: Analgesics prevelance and gender relationship among 750 students in Zagazig University (2016-2017) .

\begin{tabular}{|c|c|c|c|c|c|}
\hline Substance & Group & Males & Femals & Total & $P$ value \\
\hline abused & & $N=468(\%)$ & $N=282(\%)$ & $N=\mathbf{7 5 0}(\%)$ & \\
\hline \multirow[t]{3}{*}{ Analgesics } & Yes & 64.9 & 73.9 & 69.2 & 0.08 \\
\hline & No & 26.3 & 18.5 & 22.6 & \\
\hline & Once & 8.8 & 7.6 & 8,2 & \\
\hline
\end{tabular}


Table 3: Alcohols using and gender relationship among 750 students in Zagazig University (2016-2017)

\begin{tabular}{|c|c|c|c|c|c|}
\hline Substance & Group & Males & Femals & Total & $P$ value \\
\hline abused & & $N=468(\%)$ & $N=282(\%)$ & $N=750(\%)$ & \\
\hline \multirow[t]{3}{*}{ Alcohol } & Yes & 16.5 & 0 & 10.29 & \multirow[t]{3}{*}{$<0.0001 *$} \\
\hline & No & 67.5 & 97.9 & 89.6 & \\
\hline & Once & 6.5 & 2.1 & 4.4 & \\
\hline
\end{tabular}

* Significant.

Table 4: Sedatives and gender relationship among 750 students in Zagazig University (2016-2017)

\begin{tabular}{|c|c|c|c|c|c|}
\hline \multirow[t]{2}{*}{ Substance } & \multirow[t]{2}{*}{ Group } & Males & \multicolumn{2}{|l|}{ Femals } & \multirow[t]{2}{*}{$P$ value } \\
\hline & & $N=468(\%)$ & $N=282(\%)$ & $N=750(\%)$ & \\
\hline \multirow[t]{3}{*}{ Sedatives } & Yes & 5.2 & 5.2 & 5.2 & \multirow[t]{3}{*}{0.91} \\
\hline & No & 92.1 & 92.7 & 93.7 & \\
\hline & Once & 2.7 & 2.1 & 1.1 & \\
\hline
\end{tabular}

Table 5: Stimulants and gender relationship among 750 students in Zagazig University (2016-2017)

\begin{tabular}{|c|c|c|c|c|c|}
\hline \multirow[t]{2}{*}{ Substance } & \multirow[t]{2}{*}{ Group } & Males & Femals & \multirow{2}{*}{$\begin{array}{l}\text { Total } \\
\quad N=750 \quad(\%)\end{array}$} & \multirow[t]{2}{*}{$P$ value } \\
\hline & & $N=468(\%)$ & $N=282(\%)$ & & \\
\hline \multirow[t]{3}{*}{ Stimulants } & Yes & 6.5 & 1.25 & 4 & $0.01 *$ \\
\hline & No & 92 & 97.5 & 94.6 & \\
\hline & once & 1.5 & 1.25 & 1.4 & \\
\hline
\end{tabular}

* Significant.

Table 6: Percentage of taking sedatives, stimulants and using alcohols in relation to smoking among 750 students in Zagazig University (2016-2017)

\begin{tabular}{lrrrr}
\hline $\begin{array}{l}\text { Substance } \\
\text { Abused }\end{array}$ & $\begin{array}{r}\text { Smoker } \\
\mathbf{N = 5 7}(\boldsymbol{\%})\end{array}$ & $\begin{array}{r}\text { Non-smoker } \\
\mathbf{N = 6 9 3}(\boldsymbol{\%})\end{array}$ & $\begin{array}{r}\text { Total } \\
\mathbf{N = 7 5 0}(\boldsymbol{\%})\end{array}$ & P value \\
\hline Alcohols & 44.21 & 3.6 & 6.6 & $<0.0001^{*}$ \\
\hline Sedatives & 19.79 & 3.25 & 4.52 & $<0.0001^{*}$ \\
\hline Stimulants & 23.68 & 2.38 & 4 & $<0.0001^{*}$ \\
\hline
\end{tabular}

* Significant 
Table 7: Positive urine screening test results and its relationship to gender among 750 students in Zagazig University (2016-2017)

\begin{tabular}{ccccc}
\hline Drug screened & $\begin{array}{c}\text { Males } \\
\mathbf{N = 4 6 8}(\boldsymbol{\%})\end{array}$ & $\begin{array}{c}\text { Females } \\
\mathbf{N = 2 8 2}(\boldsymbol{\%})\end{array}$ & $\begin{array}{c}\text { Total } \\
\mathbf{N = 7 5 0}\end{array}$ & P value \\
\hline THC & 6.34 & 0 & 3.9 & $<0.0001^{*}$ \\
\hline Tramadol & 3.05 & 0.42 & 1.9 & 0.02 \\
\hline BZDs & 0.76 & 0.42 & 0.67 & 0.62 \\
\hline Opium & 0.76 & 0 & 0.47 & 0.18 \\
\hline Barbiturates & 0.76 & 0 & 0.47 & 0.18 \\
\hline Amphetamine & 0 & 0 & 0 & 0 \\
\hline Cocaine & 0 & 0 & 0 & 0 \\
\hline All drugs & 11.67 & 0.84 & 7.41 & $>0.0001^{*}$ \\
\hline
\end{tabular}

* Significant $\quad \mathrm{THC}=$ Tetrahydrocannabinol $\quad$ BZDs =Benzodiazepines

Table 8: Relationship between positive screening results and failure in an exam before among 750 students in Zagazig University (2016-2017)

\begin{tabular}{ccccc}
\hline $\begin{array}{c}\text { Failed in } \\
\text { an exam } \\
\text { before }\end{array}$ & $\begin{array}{c}\text { Yes } \\
\mathbf{N = 1 1 4}\end{array}$ & $\begin{array}{c}\text { No } \\
\mathbf{N = 6 3 6}\end{array}$ & $\begin{array}{c}\text { Total } \\
\mathbf{N = 7 5 0}\end{array}$ & $\boldsymbol{P}$ value \\
\hline THC (\%) & 7.89 & 1.89 & 1.19 & $0.003^{*}$ \\
\hline Tramadol (\%) & 6.58 & 0.94 & 1 & $0.001^{*}$ \\
\hline Opium (\%) & 1.32 & 0.24 & 0.2 & 0.17 \\
\hline BDZs(\%) & 2.63 & 0.24 & 0.39 & $0.001^{*}$ \\
\hline Barbiturates (\%) & 2.63 & 0.00 & 0.39 & $0.001^{*}$ \\
\hline All drugs & 21.05 & 3.3 & 3.17 & $<0.0001^{*}$ \\
\hline
\end{tabular}

* Significant $\mathrm{THC}=$ Tetrahydrocannabinol

\section{DISCUSSION}

_Drug addiction is a major public health and socioeconomic problems worldwide that annoy the Egyptian government. This study was done to assess drug abuse among Zagazig University students, also to identify the most common abused drug among them.

In this study, the mean age value of the studied students was $20.03 \pm 1.31$ years similar to mean age declared by Bethany et al. (2013) in adolescents admitted for substance use disorder treatment in the northeastern United States medical centers and Nahid et al. (2014) in Students of Isfahan Province, Iran who found
BZDs $=$ Benzodiazepine . that the mean (SD) age of students in their samples was 20.9 (1), 19.6(2) years, respectively.

In contrary Hamdi et al (2013) studied students from 8 governorates in Egypt showed the highest onset of substance abuse at age of 15 years old. Because of the demographic pattern that reflects availability and accessibility to drugs.

In this study, the smoking prevalence among all studied students was $16.81 \%$ and there was highly significant differences between males and females ( males $26.1 \%$ were current smokers while in total females only $1.4 \%$ ). 
These results are in agreement with the study conducted by Refaat (2004) among Suez Canal University students, the study found that current smokers were $26.5 \%$ in males, $12.2 \%$ in females). Radwan et al. (2015) found that current smokers in males about $27.5 \%$ and in females about $18.1 \%$ in a national survey done in Egypt.

In this study, the rate of smoking was higher among males than females and also in the above mentioned studies. In Egypt, culturally and socially that females cannot smoke (Adams et al., 2009).

The prevalence of analgesic (tramadol) abuse among all studied students was $69.2 \%$, total males $64.9 \%$ and total females $73.9 \%$.

These results are approximatlly similar to an Iranian study conducted by Sarahroodi et al. (2012) who found that $76.6 \%$ of the respondents reported abusing analgesics with $73.4 \%$ male and $79.2 \%$ female students.

While, in a study conducted by McCabe et al. (2008) in the United States found that $54.3 \%$ of students reported abusing analgesics. $9.7 \%$ of students reported abusing stimulants in their lifetime.

The alcohol prevalence was $10.29 \%$, this is in an agreement with Karam et al. (2007) who found that prevalence was $10.5 \%$ in his study.

In contrary Tesfaye (2014) reported that $50.2 \%$ drank alcohol at least once in their lifetime from them $53.8 \%$ in males and $38.8 \%$ in females in Ethiopia. This explained by Biratu et al. (2014) who stated that homemade alcoholic drinks are acceptable for the vast majority of Ethiopian people. Furthermore, Yuri et al. (2011) at the Federal University of Alagoas who found that regular alcohol prevalence was $29.1 \%$.

The prevalence of sedative abuse among all studied students was $5.2 \%$.

In Iranian study conducted by Rezahosseini et al. (2014) found that the prevalence of sedatives were $7.4 \%$.

Ahmed et al. (2014) found $17 \%$ of students reported taking sedative in the King Saud University Medical Students.
In this study the prevalence of stimulant abuse among all studied students was $4 \%$ is higher than a study done by Mohamed et al. (2007) in Zagazig University they found that $1.30 \%$ of students were abusing stimulants as the awareness by abusing drugs increase.

Also there were significant difference between smokers abusing drugs \&alcohol and nonsmoker abusing them.

Katie et al. (2012) identified that there was a strong association between drinking alcohol and smoking among college students. Reed et al. (2007) reported that students were significantly more like to smoke more cigarettes when they were drinking.

In a study done on college students' attitudes about smoking Dierker et al. (2006) found that the primary reason for starting to smoke, and the main reason smokers continue to smoke as reported were addiction and stress.

Similarly, in a self-administered questionnaire study among 3258 students at 11 faculties of Assiut University El-Ansari et al. (2014) found that drinking alcohols was positively associated with one's illicit drug/s use.

The most abused drug was tetrahydrocannabinol followed by tramadol then benzodiazepines, while opium and barbiturates in the same category.

These was in an agreement with Webb (2006) who conducted a study on united kingdom university students, it had been found that tetrahydrocannabinol was the most common drug abused explained by their families was common in the locality with relatively low price, followed by tramadol and there was significant relationship between drug abuse and being male.

In contrary, Adeyemo et al. (2016) reveals that alcohol was the most commonly abused drugs amongst University Students in Benin City, Nigeria. And Maria et al. (2015) who conducted a survey on 275 university students in a private institution in Brazil found that alcohol was the most widely used drug, followed by tobacco, and marijuana then psychoactive drugs. 
Mwaheb et al. (2012) conducted a study in Fayom city on male students they found that $75 \%$ of them were abusers of drugs. They reported that the common drugs of abuse were $40 \%$ cannabis, $37 \%$ tramadol, and $23 \%$ benzodiazepine. These percentages are higher than the current study may be due to that the study was among males only.

In contrary, A North American study entitled Monitoring the Future reported the following data regarding the prevalence of drug use by university students over a year: alcohol $(82.1 \%)$; tobacco $(30.0 \%)$; and marijuana $(32.3 \%)$. These are evidence that the high rate of use of alcohol followed by the use of tobacco and marijuana is a reality worldwide and, thus, use of drugs is a global public health issue (Josefina et al., 2007).

In this study, The percentages of positively screened students of all studied population were $3.9 \%, 1.9 \%$, $0.67,0.47$ and $0.47 \%$ for tetrahydrocannabinol, tramadol, Benzodiazepine, opium and barbiturate while there was negative screening for the amphetamin and cocaine.

In screening for drug of abuse El-Ezz and Ez-Elarab (2011) in Ain Shams University found that $87.2 \%, 12 \%$ and $3.3 \%$ of students were analgesics, sedatives and stimulants.

But it found that negative amphetamines and cocaine screening results this came in agreement with study conducted by Werese and Hambisa (2014) in Ethiopia and Goreishi and Shajari (2013) in .Iranian study .

There was strong association between positively screened students and failure in the exam before.

Similarly, the study in Colombia concluded that drug abuse was a major problem and the cause in university students reported a higher default and dropout in this population group, school dissatisfaction, a higher amount of repetitions in the courses and low academic performance (Castaño-Perez and Calderon-Vallejo, 2014).

Tarig et al. (2016) carried a study in sudan university students and found that Curiosity $(33.1 \%)$ was the main reason for initiation of substance abuse. The main adverse effects reported were health problems $(19.7 \%)$ and theft (19.7\%). Peers (40.9\%).

\section{RECOMMENDATIONS}

Large population-based studies that involve at-risk groups (adolescents and young adults) are needed to estimate the risk factors, and consequences of substance abuse in Egypt. We recommend that future longitudinal studies be conducted to investigate the risk factors of drug abuse and suggest the use of urine analysis for drugs of abuse for all students before joining the university.

The present study also necessitate a prevention programm regarding drug addiction in zagazig university.

\section{REFERENCE}

1. Adams, M.L.; Jason, L.A.; Pokorny, S. and Hun,t Y. (2009): The relationship between school policies and youth tobacco use. J. School. Health.; 79(1): 17-23.

2. Adeyemo, F.; Ohaeri, B.; Pat, U. and Okpala, O. (2016): Prevalence of Drug Abuse Amongst University Students in Benin City, Nigeria. Public. Health. Rese.; 6(2): 31-37

3. Ahmed, A.; Abdualltef, H.; Al-Rashoudi, A.; AlEisa, M.; Addar, H. and Abdullah H. (2014): Sedative Drug Use among King Saud University Medical Students: A Cross-Sectional Sampling Study. Depress. Res. Treat.; 14: 378-379.

4. Bethany, K. B.; John, R. and Kevin, P. (2013): Sex, age, and progression of drug use in adolescents admitted for substance use disorder treatment in the northeastern United States: Comparison with a national survey. Subst. Abus.; 34(3): 263-272.

5. Biratu, A.k. Seyoume, F.T. and Dubi, A.Y. (2014): Prevalence and factors determining psychoactive substance (PAS) use among Hawassa University (HU) undergraduate students, Hawassa Ethiopia. B.M.C.; 14:10-44.

6. Castaño-Perez, G.A. and Calderon-Vallejo, GA. (2014): Problems associated with alcohol consumption by university students. Rev. Lat. Am. Enfermagem.; 22:739-46.

7. Dierker, L.; Lloyd-Richardson, E.; Stolar, M.; Flay, B.; Tiffany, S. and Collins, L. (2006): The proximal association between smoking and alcohol use among first year college students. Drug and Alcohol Dependence.; 81:1-9.

8. El-Ansari, W.; Sebena, R. and Labeeb, S. (2014): Multiple risk factors: Prevalence and correlates of alcohol, tobacco and other drug (ATOD) use among university students in Egypt. J. Subst. Use.; 20:380388.

9. El-Ezz, N.F. and Ez-Elarab, H.S. (2011): Knowledge, attitude and practice of medical students towards self 
medication at Ain Shams university, Egypt. J. Prev. Med. Hyg.; 52:196-200.

10. El-Masry, M.K. and Tawfik, H.M. (2013): Annual Report of the poison control centre of Ain Shams University Hospital, Cairo, Egypt. Ain. Shams. J. Forensic. Med. Clin. Toxicol. 2; 20:10-7.

11. El-Sawy, H. Hay, M.A. and Badawy, A. (2010): Gender differences in risks and pattern of drug abuse in Egypt. Egypt J. Neurol. Psychiatry. Neurosurg.; 47:413-418.

12. Goreishi, A. and Shajari, Z. (2013): Substance abuse among students of Zanjan's universities (Iran): A knot of today's society. Addict. Health.; 5:66-72.

13. Hamdi, E.; Gawad, T.; Khoweiled, A.; Sidrak, A.E.; Amer, D.; Mamdouh, R.; Fathi, H. and Loza, N. (2013): Lifetime prevalence of alcohol and substance use in Egypt: a community survey. Subst. Abus.; 34(2):97-104.

14. Hamedi, E.; Sabry, N.; Sedrak, A.; Khowailed, A. and Loza, N. (2016): Sociodemographic Indicators for Substance Use and Abuse in Egypt. J. Addict. Prevent.; 4(1): 8.4.

15. Josefina, A.; Leonard, A.; Bradley, D. and Margaret, I. (2007): Substance Abuse Prevalence and Treatment Among Latinos and Latinas. J. Ethn. Subst. Abuse.; 6(2): 115-141.

16. Karam, E.; Kypri, K. and Salamoun, M. (2007): Alcohol use among college students: an international perspective. Psych.; 20 (3): 213-221.

17. Katie, W.; Barbara,C. and Mary E. (2012): Larimer Concurrent Drinking and Smoking among College Students: An Event-Level Analysis. Psychol. Addict. Behav.; 26(3): 649-654.

18. Maria, T.; Zeferin, H. and Bruna B. (2015): Drug consuption among university students: family, spirituality and entertainment moderating influence of pairs. Psych.; 25:1-15.

19. McCabe, S.E.; Teter, C.J. and Boyd, C.J. (2008): Medical use, illicit use and diversion of prescription stimulant medication. J. Psychoactive. Drugs.; 38:4356.

20. Mohamed, M.B.; Abd El-Hammed, E.H.; Sherif, N.A. and El-Sharkawy, G.F. (2007): Drug Abuse Among Zagazig University Students Prevalence and Risk Factor. Master Thesis in Public Health, Zagazig University. P. 158.

21. Monirpoor, N.; Khoosfi, H.; Gholamy, M.; Tamaddonfard, M.; Tabatabaei, S.F. and Mohammad, (2014): Vulnerability to substance abuse and the risk of suicide in students of region 12 of islamic azad university. Int. J. High. Risk. Behav. Addict.; 3:111122.
22. Mwaheb, M.A.; El-Galad, G.M.; Dawood, A.A. and El-sayed, S.H. (2012): Drug Abuse Among Students in (Schools and Colleges) in Fayoum city. MD Thesis, Forensic Medicine and Clinical Toxicology, Fayoum University. P. 274.

23. Nahid, G.; Leila, G.; Shohreh, A.; Fatemeh, M.; Mahmonir, N.; Ziba, F.; and Kamal, H. (2014): Development of a Questionnaire to Assess Drug Abuse among High School Students of Isfahan Province, Iran: An Action ResearchInt J Prev Med.; 5(2): 146-153.

24. Radwan, G.; Eltahlawy, E.; El-Setouhy, M.; Magder, L. and Hussein, M. (2015): Estimates of the Prevalence of Tobacco Smoking in Egypt. Open J. Epidem.; 5: 129-135.

25. Reed, M.B.; Wang, R.; Shillington, A.M.; Clapp, J.D. and Lange, J.E. (2007): The relationship between alcohol use and cigarette smoking in a sample of undergraduate college students. Addict. Behav.; 32:449-464.

26. Refaat, D. (2004): Stages in adolescent involvement in drug use. Scie.; 190(4217):912-914.

27. Rezahosseini, O.; Roohbakhsh, A.; Tavakolian, V. and Assar, S. (2014): Drug abuse among university students of Rafsanjan, Iran. Iran. J. Psychiatry. Behav. Sci.;8:81-5.

28. Sarahroodi, S.; Maleki-Jamshid, A.; Sawalha, A.F.; Mikaili, P. and Safaeian, L. (2012): Pattern of selfmedication with analgesics among Iranian university students in central Iran. J. Family. Community. Med.;19:125-9.

29. Tarig, O.; Cathrine, V.; Alaa, A.; Hala, M.; Fatima, A.; Asma, A.; Eiman, A. and Wael, M. (2016): Epidemiology of Substance Use among University Students in Sudan. J. Addict.; 2: 24-30.

30. Tesfaye, G. (2014): Practice and awareness of health risk behaviour among Egyptian university students. East. Mediterr. Health. J.; 10:72-81.

31. Webb, A. (2006): Drug Use and Cognitions About Drug Use Amongst Students: Changes Over the University Career. J. Youth. Adolescence.; 31(3): 221229.

32. Werese, A. and Hambisa, M.T. (2014): Substance use and associated factors among university students in Ethiopia: A cross-sectional study. J. Addict.; 5: 221231.

33. Yuri, S.; Toledo, B.; Divanise, S.; Maria, S.; Jakeline, A. and Thallyta, M. (2011): The prevalence of alcohol consumption among the students newly enrolled at a public university. J. Pharm. Bioallied. Sci.; 3(3): 345349. 


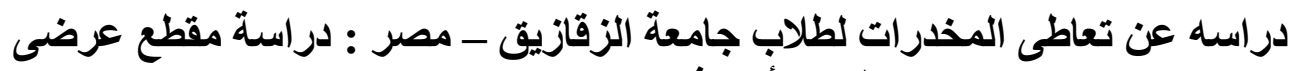

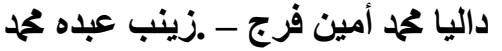

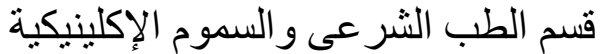

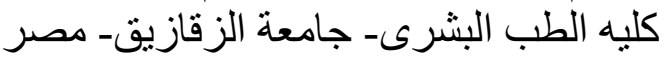

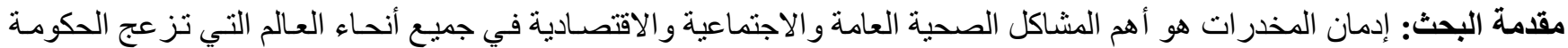

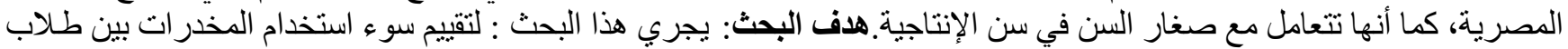

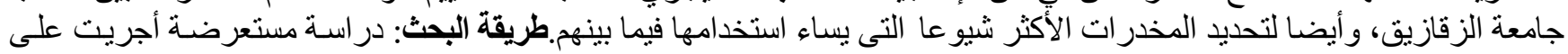

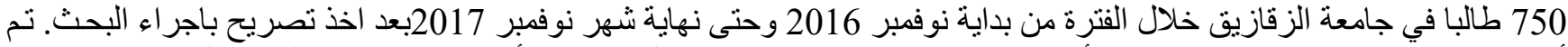

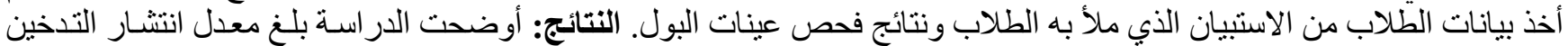

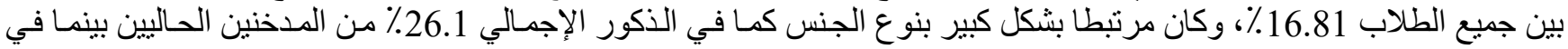

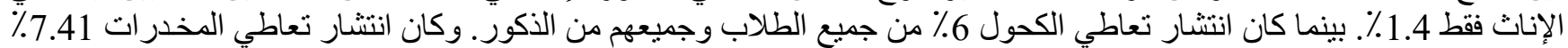

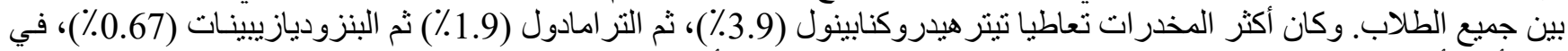

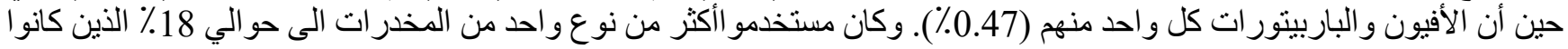

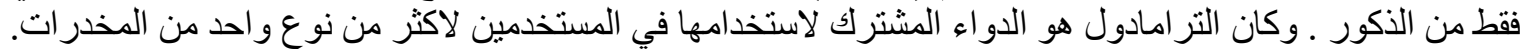

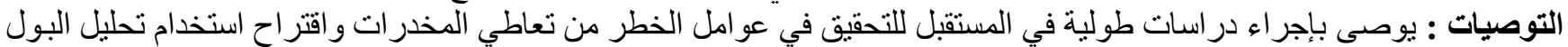

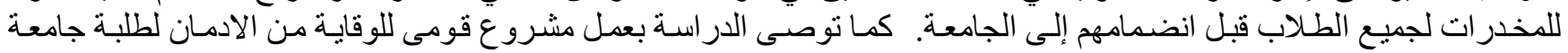

